\title{
ZELLIG HARRIS: 50 ANOS DEPOIS
}

\author{
Carlos Alberto Faraco*
}

$\mathrm{M}$

eu objetivo com este texto nesta mesa-redonda é fazer um registro dos 50 anos da publicação do artigo de Zellig Harris que - ao que tudo indica - foi o primeiro a usar a expressão "Discourse analysis" que pode ser traduzida indistintamente por Análise do Discurso ou Análise de Discurso.

Esse artigo foi publicado no número 28 da revista Language, em 1952. Foi reimpresso no livro editado por Fodor e Katz - The structure of language em 1964 e teve uma tradução francesa publicada na revista Langage número 13, em 1969.

Essa tradução francesa decorre do interesse de M. Pêcheux pela proposta de Harris ao tempo em que lançava seu projeto de um tratamento automático da superfície textual.

Vou aqui fazer este registro por meio de uma rápida revisita ao texto e externando algumas reflexões que me vieram nessa revisita. Não sou o único que, nos últimos tempos, revisitou o Harris. Há 5 anos, no Seminário Internacional de Análise do Discurso realizado na UFMG, o prof. Samuel Moreira da Silva apresentou reflexões advindas de sua releitura do Harris, numa mesa-redonda que abordava alguns precursores da Análise do Discurso. Pretendo aqui conversar um pouco também com este texto.

$\mathrm{O}$ artigo de Harris tem 5 partes:

* Universidade Federal do Paraná. 
- Apresentação;

- Parte 1-Preliminares;

- Parte 2 - Método;

- Parte 3 - Resultados;

- Parte 4-Suma do texto.

Pode-se dizer que a Parte 2 contém o coração do texto e a Parte 3 apresenta os resultados da aplicação exemplificativa do método. Na Apresentação, o autor conceitua discurso, reservando para o termo dois sentidos complementares: discurso é o lingüístico que ultrapassa os limites da sentença e discurso é o conglomerado não arbitrário de sentenças.

O primeiro sentido - a idéia de um nível superior à sentença - se justifica pelo próprio envolvimento de Harris com uma lingüística de níveis; o segundo atribui a esse nível superior uma organização, o que, por si, dá sustentação à proposta de uma análise.

Em seguida, o autor classifica seu método de formal, na medida em que enfoca a distribuição dos elementos lingüísticos em ambientes lingüísticos por meio de critérios puramente morfossintáticos e sem depender do conhecimento que temos do significado desses elementos - o que novamente não surpreende, considerando sua filiação ao distribucionalismo americano.

O objetivo de Harris, com o desenvolvimento desse método formal, é estabelecer padrões de recorrência dos elementos lingüísticos de tal modo que podemos não saber o que o texto está dizendo, mas podemos descobrir como está dizendo.

Na seqüência, Harris vai dizer que os métodos criados para o estudo da sentença são suficientes para analisar o que vai além dela. Com isso, ele preserva o pressuposto distribucionalista dos níveis e garante uniformidade metodológica para sua proposta, o que revela uma certa prudência em não multiplicar o que não precisa ser multiplicado.

A Análise do/de Discurso (AD) não seria para Harris, portanto, um novo método, mas a expansão do velho método a um novo objeto, objeto que, no fundo, se distingue do velho objeto apenas na sua extensão. Continua sendo um objeto recortado no estritamente lingüístico e analisado exclusivamente em sua imanência. A AD seria uma análise apenas intralingüística.

Samuel Moreira da Silva vai dizer que, nesse sentido, Harris trouxe a ilusão de que há uma "verdade do texto" (imanente) e o sonho de um tratamento gramatical neutro, alheio - como diz ainda o Samuel - a toda humana lide.

Se o método distribucional tem essa ilusão e está alheio a toda humana lide, Harris deixa claro - nos seus preliminares - que ele não está alheio a essa 
questão. Lembra que há uma correlação entre discurso e a situação social em que ele ocorre. Critica, contudo, os estudos que pretendem enfocar essa correlação por não se utilizarem dos métodos formais da lingüística. E, por outro lado, diz que tal correlação discurso/situação foi sempre considerada como estando fora do escopo da lingüística.

Cinqüenta anos depois, parece que estamos no mesmo lugar: ainda justificamos a necessidade da $\mathrm{AD}$ porque as questões da relação discurso/ situação estão fora do escopo da lingüística stricto sensu; e ainda somos criticados por não nos utilizarmos dos métodos formais da lingüística.

Dois comentários de Harris nesta Parte 1 de seu artigo merecem registro. O primeiro nos remete à nota 2 do texto, quando ele faz menção à relação entre língua e personalidade, ou, em outros termos, ao estudo das características individuais do texto (um problema tradicional para $\mathrm{AD}$ face à candente questão do assujeitamento do sujeito).

Nessa nota, Harris diz que essa relação é parte da relação língua/sociedade porque as características individuais emergem das experiências individuais com situações interpessoais socialmente condicionadas. Quer dizer: o método está, em princípio, alheio à humana lide, mas o pesquisador não. A ponto de ele (eu diria surpreendentemente para muitos lingüistas) reconhecer que o individual emerge de relações interpessoais socialmente condicionadas.

No segundo comentário, Harris nos diz que a correlação entre discurso e situação não significa: a) que discursos ocorrendo em situações similares devem necessariamente ter certas características formais em comum; e b) que discursos ocorrendo em situações diferentes devem necessariamente ter características formais diferentes. Em suma, a correlação discurso/situação não é do tipo um-a-um.

Este comentário de Harris pode parecer óbvio como pressuposto geral de qualquer $\mathrm{AD}$. Contudo, algumas vezes, lendo trabalhos que se classificam como $\mathrm{AD}$, não me parece que esse pressuposto esteja claramente estabelecido em certas análises.

Cinqüenta anos depois, parece (e essa é uma impressão de leitor) que certas análises - imbuídas que estão de um certo ardor inquisitorial - não se deram conta, na prática, de que a relação discurso/situação não é biunívoca. Parece que não se deram conta, na prática de análise - de outros pressupostos que poderíamos correlacionar com o de Harris, ou seja, do pressuposto do primado da heterogeneidade, do interdiscurso, do intertexto. Análises que ainda entendem, na prática, que os processos discursivos podem ser reduzidos a um novo capítulo da velha luta do Santo Guerreiro contra o Dragão da Maldade. 
Voltando ao texto de Harris, lembramos que, como dissemos antes, seu coração está no capítulo do método. Seu texto é, fundamentalmente, um esforço para precisar os procedimentos analíticos; para precisar o modo de estender o método da lingüística distribucional ao supra-sentencial ou ao aglomerado não arbitrário de sentenças.

E não cabe, claro, repisar aqui todos os detalhes do seu caminho. Lembro apenas que tudo se faz nesse ponto do texto para cuidadosamente viabilizar ao analista um procedimento para se estabelecer classes de equivalências entre segmentos do supra-sentencial com base na sua distribuição. São essas classes de equivalência, segundo crê o autor, que vão nos revelar os padrões de recorrência e como o texto sob análise está organizado.

Novamente, dois pontos merecem comentário. Primeiramente, destacar que Harris está formulando o problema da recorrência - que é, talvez, o grande problema ou um dos grandes problemas de quem lida com o texto, ou seja, mostrar (para além do apenas intuitivo) que os enunciados são internamente conectados; que nossas seqüências verbais são não arbitrárias.

O problema formulado por Harris continua, 50 anos depois, entre nós e pouco saiu do nível do intuitivo. O que não nos seduz mais, obviamente, é a resposta que ele deu ao problema. Sobre isso, Samuel Moreira da Silva diz duas coisas: a) que o método de Harris é mais fácil de compreender do que de aplicar; b) o distribucionalismo já passou, é caduco.

Samuel diz também que a análise de Harris não saiu do projeto (e diz, com certa ironia: "feliz ou infelizmente? - haverá quem pergunte") e encerrou sua carreira apenas como esboço - com a pretensão de dizer coisas sobre vasto domínio - o que, aparentemente, Samuel considera ruim. Mas, podemos perguntar: não será essa a pretensão de todos os que lidam com questões lingüísticas?

Samuel lembra as influências que o texto exerceu sobre o pensamento de Pêcheux que, num certo momento, se inspirou em Harris na pretensão (digo eu) de estabelecer o dispositivo formal para o registro da superfície discursiva, a fase de análise propriamente lingüística da $\mathrm{AD}$.

Poderíamos lembrar também que o objeto discurso como recortado por Harris - isto é, como o supra-sentencial, como a seqüência falada ou escrita internamente conectada - continua sendo objeto para várias tendências que se classificam de $\mathrm{AD}$ e que não descartaram in totum uma perspectiva distribucionalista.

Vamos ao segundo ponto. Ao lermos o texto do Harris, temos a oportunidade de flagrar um lingüista envolvido com a construção do método. Fica mais que visível seu comprometimento com a questão metodológica, com o rigor dos procedimentos. 
E aí me ocorreu a pergunta: não deveríamos nós em $\mathrm{AD}, 50$ anos depois, retomar esse tipo de comprometimento? E, ao colocar essa questão, quero deixar claro que não vai aqui nenhuma proposta de retomada positivista, de um revisionismo abominável.

Parece que podemos concordar com alguns grandes pressupostos:

- que a resposta de Harris não nos seduz;

- que aceitamos, pelo menos em algumas ADs, que nossa disciplina é do reino da interpretação;

- que nosso objeto não se dá a priori (pelo menos em algumas ADs), mas é a reflexão que deve visar a construí-lo (nesse sentido, ele é ponto de chegada e não de partida);

- que lidamos com a significação (ao contrário de Harris);

- que a significação é deslizante, perpetuamente deslizante (seja pelo trabalho do consciente, do não-consciente ou do inconsciente).

Tudo isso parece certo. Contudo, apesar da fluidez da área, me pergunto: não devíamos nos ocupar um pouco mais com nossos problemas metodológicos?

Ou nos satisfazem as análises que se esgotam na paráfrase; na asseveração sem demonstração; no ardor inquisitorial; na banalização das relações do dizer com os processos inconscientes?

\section{RESUMO}

O texto faz uma leitura do artigo "Discourse Analysis", de Zellig Harris, comemorando os 50 anos de sua publicação. Levanta, a partir dessa leitura, uma reflexão sobre problemas de ordem metodológica em Analise do/de Discurso.

Palavras-chave: Zellig Harris, discurso, metodologia.

\section{ABSTRACT}

The text intends to celebrate the $50^{\text {th }}$ anniversary of the publication of Zellig Harris' article "Discourse Analysis". It ends up with a general question about methodological problems in Discourse Analysis.

Key-words: Zellig Harris, discourse, methodology. 
FARACO, C. A. Zellig Harris: 50 anos depois

\section{REFERÊNCIAS}

HARRIS, Z. Discourse analysis. Language, New York, v. 28, n. 1, p. 1-30, 1952.

SILVA, S. M. da. Harris - o discurso e a questão da forma: controvérsias e perspectivas. In: MARI, H. et al. (Orgs.). Fundamentos e dimensões da análise do discurso. Belo Horizonte: Carol Borges - Núcleo de Análise do Discurso/Fale - UFMG, 1999. p. 173188. 